\title{
Biosynthesis, characterization of PLGA coated folate-mediated multiple drug loaded copper oxide (CuO) nanoparticles and it's cytotoxicity on nasopharyngeal cancer cell lines
}

\author{
Long-Mei Guo, Xue-Mei Xu, Dong Zhao, Xun-Gong Cai and Bin Zhou*
}

\begin{abstract}
Cytotoxicity of CuO nanoparticles (NPs) are an impediment in utilizing them as an effective nanocarriers of chemotherapeutic drugs for targeted drug delivery in nasopharyngeal cancer. In our current study, we have designed a two-step synthesis and coating of CuO NPs with different concentrations of PLGA (polylactide-co-glycolide) to reduce the cytotoxicity. This was further conjugated with folic acid to enhance targeting to specific tissue. The multiple drugs loaded in the NPs were two potent anticancer drugs doxorubicin and docetaxel. A complete characterization studies including micrographic analysis, zeta potential measurements, polydispersity index, Fourier transform infrared spectroscopy (FTIR), encapsulation and loading efficiencies, stability and in vitro release studies were done. Cytoxicity studies were done with MTT 3-(4,5-dimethylthiazol-2-yl)-2,5-diphenyltetrazolium bromide assay, acridine orange/ethidium bromide and DAPI (4, 6-diamidino-2-phenylindole, dihydrochloride) staining procedures. Impediametric studies were also carried out to reinforce the reduction in cytotoxicity. Finally the cellular uptake of the NPs was seen. It was evident from the results that the multiple drugs loaded CuO NPs formed with PLGA coating were uniform, non-agglomerated in size ranging from 180 to $195 \mathrm{~nm}$. The FTIR revealed no major changes in drug peaks. Encapsulation and loading efficiencies showed sufficient amount of drug being loaded into the NPs. The drug loaded NPs showed no change in size or zeta potential even after a period of 30 days. The cytotoxicity studies revealed significant reduction in toxicity after coating the surface treated with PLGA as evident from the microscopic analysis of cells. Hence the current study may be prioritized and further in vivo/in vitro studies may be carried out.
\end{abstract}

Keywords: Copper oxide, Nasopharyngeal, Cytotoxicity, Impediametric, Folate

\section{Introduction}

A subvariant of head and neck carcinoma, nasopharyngeal carcinoma is a rare kind of carcinoma which affects the population of Southeast Asia, China and USA in a major manner (Lam et al. 2016; Chua et al. 2016). It has been reported that nasopharyngeal carcinoma generally has three subtypes which affects adults and children separately (Sobin 1991). It has also been noted that

\footnotetext{
*Correspondence: vearnalsvdtInw@gmail.com

Department of Otolaryngology, The Fourth Affiliated Hospital of Harbin Medical University, No. 37 of Yiyuan Street, Nangang District, Harbin 150001, Heilongjiang, China
}

conventional therapies to counteract nasopharyngeal carcinoma is accompanied by several detriments. The conventional therapy includes cytotoxic drugs treatment, radiation and finally surgical removal of the tumor (Sharma et al. 2016). Teratogenicity and cytotoxicity are two of the most severe detriments of anticancer chemotherapeutic agents (Sharma et al. 2016; Nobili et al. 2006). Furthermore, development of resistance against the drugs frequently results in increasing the dosage of the same, thus worsening the problem.

An alternate pathway to circumvent the toxicity and lessen the dosage of the anticancer drugs is by the means 
of encapsulating them in nanocarrier vehicle specifically targeting them to the targeted tissue (Sharma et al. 2016; Sun et al. 2008; Veiseh et al. 2010; Davis et al. 2010). The advent of nanotechnology provides an opportunity to synthesize nanocarriers in sub-micron range (1-100 nm) like liposomes, nanoparticles and cubosomes etc. which are extremely suitable for targeted drug delivery (Ahamed et al. 2015). Because of their sub-micron size they have enhanced penetrative properties which may disrupt the function of the targeted cells (Jiang et al. 2008; Magaye and Zhao 2012). These nanoparticles have increased time of deposition and retention in the body tissues (Madl and Pinkerton 2009). Metal nanoparticles especially copper oxide $(\mathrm{CuO})$ nanoparticles are high on the radar of investigations because of their several interesting properties. $\mathrm{CuO}$ nanoparticles however have garnered interest owing to their unique properties of photovoltaics and photoconduction (Chang et al. 2005). However despite such interesting properties, the risk of humans coming in contact with $\mathrm{CuO}$ is undisputed. A significant challenge is estimating the toxicity of $\mathrm{CuO}$ nanoparticles and ways of diminishing it. There have been innumerable studies stating that leaching of $\mathrm{Cu}$ ions in the tissues may be a potential mechanism of increase in toxicity (Ahamed et al. 2015; Chusuei et al. 2013). Therefore in our study, a key challenge was to reduce the cytotoxicity of the $\mathrm{CuO}$ nanoparticles. We have therefore formed a coating of PLGA over the $\mathrm{CuO}$ nanoparticles to render them biocompatible. Alternatively natural substances have been used regularly to reduce the side effects of metal nanoparticles. Biocompatibility and non-immunogenic properties are associated with PLGA (Majumder et al. 2018).

Therefore, we reported the biosynthesis of novel $\mathrm{CuO}$ nanoparticle loaded with paclitaxel, docetaxel, coated with PLGA and conjugated with folic acid. It has also been studied that folate (folic acid) conjugated nanoparticles are utmost effective as cancer conjugation moieties (Samadian et al. 2016). Folate receptors have increased affinity towards folate moieties which are overly expressed in malignant cells when equated to regular cells (Khoshgard et al. 2014; Zhang et al. 2016). Doxorubicin and docetaxel have been used successfully used in chemotherapeutics of nasopharyngeal carcinoma and are established anti-cancer drugs. The main objective of our study was to reduce the cytotoxicity of the $\mathrm{CuO}$ nanoparticles by coating them with PLGA and hence synthesis of a biocompatible nanoparticle carrier which carried multiple drug to targeted tissue without causing any damage to surrounding tissues. In this study we established that PLGA coating over $\mathrm{CuO}$ nanoparticles seriously tweaked the surface properties of the nanoparticle and will improve the biodegradation of the nanoparticle inside body. Alongside the synthesis of nanoparticles, it has been suggested by scientific experts to characterize the particular nanoparticle before its toxicity studies (Chang et al. 2012). Hence characterization studies including micrographic analysis, in vitro drug release, encapsulation and loading efficiency, stability studies, zeta potential analysis, polydispersity index (PDI) of the PLGA coated drug loaded $\mathrm{CuO}$ nanoparticle was carried out too.

\section{Materials and methods Materials}

PLGA (Resomer RG 85:15H), Polyvinyl alcohol (PVA, MW: 30000-70000), $\mathrm{CuCl}_{2}$ were procured from Sigma Aldrich, China/Docetaxel and doxorubicin were procured from Chengdu Mansite Pharmaceutical Co., Ltd. from Sichuan, China. Shanghai LeiDi biotechnology Co. Ltd. from Shanghai, China provided human nasopharynx carcinoma cells (HNE-1). RPMI medium 1640 procured from Gibco, Waltham, MA was used to culture the HNE-1 cells augmented with 10\% FBS also procured from Gibco, Waltham, MA. The entire procedure was carried out at physiological temperature $\left(37^{\circ} \mathrm{C}\right)$ in an incubator with $5 \% \mathrm{CO}_{2}$ \& humidity for scheduled time period utilizing allied process.

\section{Preparation of PLGA coated folate mediated CuO nanoparticles (NPs)}

Following some previously performed studies, to $50 \mathrm{~mL}$ of $1 \%$ water-soluble PLGA solution, a mixture of $0.25 \mathrm{mg}$ of $\mathrm{CuCl}_{2} \& 2 \mathrm{~mL}$ of sterile water was added to begin a reaction. Continuous stirring of the subsequent mixture was carried out for $6 \mathrm{~h}$ and the temperature at about $80{ }^{\circ} \mathrm{C}$ was throughout maintained which led to the development of PLGA-CuO NPs. The synthesis process was carried out using three varied concentrations of PLGA $0.5 \%, 1 \%$ and $2 \%$ to depict the advantage of PLGA coating over the $\mathrm{CuO}$ NPs during drug encapsulation and release respectively. The PLGA-CuO NPs synthesized with $0.5 \%, 1 \%$ and $2 \%$ PLGA concentrations were termed as C-1, C-2, C-3 respectively, and the NPs were obtained by the mechanism of freeze-drying. The procedure was adapted with finer modification from Kannan et al. (Varukattu et al. 2020) and (Vivek et al. 2014). Following this, $4.5 \mathrm{mg}$ of folic acid was mixed in $5 \mathrm{~mL}$ of dimethyl sulphoxide (DMSO). Next, in a ratio of folic acid/DCC 1:1, continuous stirring was done for $2.5 \mathrm{~h}$ in a $\mathrm{N}_{2}$ atmosphere. Finally, PLGA-CuO NPs were added with continuous stirring in same conditions for another $2 \mathrm{~h}$. Thereafter, modified FOL-PLGA-CuO NPs nanoparticles were finally twice washed with water followed by freeze-drying. 


\section{Preparation of multiple drug loaded formulations}

Anticancer drugs docetaxel and doxorubicin which are sparingly water soluble were loaded inside the FOLPLGA-CuO NPs (C-1, C-2, C-3) respectively. The procedure was adapted from Kannan et al. (Varukattu et al. 2020) with definite modifications. $5 \mathrm{mg}$ of freeze-dried C-1, C-2 and C-3 were added to $25 \mathrm{~mL}$ of Milli-Q water and by addition of $1 \mathrm{~mL}$ of doxorubicin and docetaxel mixture (concentration of drug was taken as $1 \mathrm{mg} / \mathrm{mL}$ each) within the resultant solution. Continuous stirring was carried out for $12 \mathrm{~h}$ at $37^{\circ} \mathrm{C}$. The FOL-PLGA$\mathrm{CuO}$ NPs acquired with $0.5 \%, 1 \%$ and $2 \%$ concentration of PLGA were named as CD-1, CD-2 and CD-3 respectively. CD-1, CD-2, CD-3 were dialyzed for $24 \mathrm{~h}$. against Milli-Q water The resultant suspension was investigated using UV Vis spectrophotometer and were freeze-dried. These free dried NOs were used to carry out additional experiments.

\section{Physical characterization of the PLGA-CuO NPs}

The morphological analysis of the CuO NPs, FOL-PLGA$\mathrm{CuO}$ NPs and CD-1, CD-2 and CD-3 were done both by scanning and transmission electron microscopy (SEM \& TEM). Following dispersion in water, coating of the nanoparticles with gold was done on aluminium stub assisted with double sided carbon tape ensuing a drop method. Gold sputter coating unit was utilized for $10 \mathrm{~s}$ at $10 \mathrm{~Pa}$ vacuum to coat the respective nanoparticles. $30 \mathrm{kV}$ was the distinctive acceleration potential used following which the image was shot at the selected magnification. EDX analysis was also done via SEM to check the presence of elemental copper.

TEM of the CuO NPs, FOL-PLGA-FA-CuO NPs and CD-1, CD-2 and CD-3 was done with high resolution Tecnai G2 30 (FEI, Netherlands) microscope reinforced with twin lens, power being $80 \mathrm{kV}$ and the electron source being LaB6. Upon a copper grid (300 mesh) coated with carbon, a single drop of nanoparticle was positioned carefully with the excess being soaked up with an absorbent paper. $1 \%$ sodium phosphotungstate solution was utilized for staining the nanoparticles and photomicrographs were seen at magnification up to 1000,000 $\mathrm{X}$. Air-drying and incubation of the NPs were carried out for $12 \mathrm{~h}$ following which the TEM images were perceived. The procedure was adapted with few changes from (Malamatari et al. 2015). FTIR analysis was carried out to determine the properties of the constructed NPs. The instrument utilized was IRAffinity-1S FTIR spectrophotometer (Shimadzu) with wavelength ranging from 400 to $4000 \mathrm{~cm}^{-1}$. This instrument provides $30000: 1$ ratio with an accumulation of single minute, neighbourhood of $2100 \mathrm{~cm}^{-1}$, and resolution of $0.5 \mathrm{~cm}^{-1}$ maximum. $\mathrm{CuO}$ nanoparticles, PLGA-CuO NPs and CD-1, CD-2 and CD-3 were reorganized in sterile water for purification before the procedure.

\section{Particle size, polydispersity index (PDI) and Zeta potential measurement studies}

For calculation of mean diameter, size distribution (PDI) and zeta potential of $\mathrm{CuO}$ nanoparticles, FOL-PLGA$\mathrm{CuO}$ NPs and CD-1, CD-2 and CD-3, Delsa Nano C Zetasizer was deployed. The readings were obtained at physiological temperature. Weighing and dispersion of the freeze-dried nanoparticles in Milli-Q water was done earlier for dilution along with achieving a suitable scattering intensity. Measurement of each sample was done thrice. Implementation of the experiment was carried out at $25{ }^{\circ} \mathrm{C}$. The mean of three measured values of electrophoretic mobility was finally accepted as the optimum $\zeta$ potential values.

\section{Determination of encapsulation efficiency (EE\%) and loading efficiency (LE\%) of the nanoparticles}

The procedure was followed with suitable changes from (Zhang et al. 2018; Wei et al. 2017) with changes to suit our experiments. CD-1, CD-2 and CD-3 were centrifuged at 10,000 rpm (High Speed Centrifuge, TGL-16B, Shanghai, China) for 20 min leading to the separation of docetaxel and doxorubicin from the NPs. With a $0.45-\mu \mathrm{m}$ filter, the supernatant was collected.

An HPLC system (Agilent, US) having the following prerequisites was used for the investigation of free drugs in CD-1, CD-2 and CD-3: a TCC 300 C18 column (250 mm $\times 4.6 \mathrm{~mm}, 5 \mu \mathrm{m})$, a identifying wavelength of $425 \mathrm{~nm}$ and a mobile phase of 7.5:7.5:85, v/v of methanol/acetonitrile/ $0.4 \%$ aqueous phosphoric acid and the flow rate of $1 \mathrm{~mL} / \mathrm{min}$. After CD-1, CD-2 and CD-3 were dissolved in ethanol; the amount of the total drug loaded was calculated. The multiple drug encapsulation efficiency (EE) along with loading efficiency (LE) was the result of the following formulae:

$$
\begin{aligned}
& E E(\%)=\text { Encapsulateddrug } \div \text { Totaldrug } \times 100 \% \\
& L E(\%)=\text { Totaldrug } \div \text { NPs } \times 100 \%
\end{aligned}
$$

The equations were employed to decide the $\mathrm{EE}$ and LE\% of CD-1, CD-2 and CD-3.

\section{Stability studies}

The stability of CD-1, CD-2 and CD-3 were tested at room temperature where $10 \mathrm{mg}$ of NPs were disseminated in $50 \mathrm{ml}$ of Milli-Q water through sonication. Visual observation of settling of NPs were carefully made which was followed by size distribution measurement, 
polydispersity index and zeta potential of the NPs at steady time interlude of 10,20, 30 days using the Delsa Nano C Zetasizer to note the aggregation of NPs.

\section{In vitro drug release from the NPs}

Here in our study, we implemented a marginally divergent approach for the release of drugs in vitro into the medium. A dialysis bag $(3 \mathrm{ml})$ was taken and $2.5 \mathrm{ml}$ of each CD-1, CD-2 and CD-3 were loaded into it. For unimpeded dissolution outsized undissolved molecules were permitted to diffuse out through the dialysis bag. The dialysis bag was retained in $2.5 \mathrm{~L}$ of $10 \mathrm{mM}$ phosphate buffer solutions ( $\mathrm{pH}-7.4$ and 4.5$)$ where after every $3 \mathrm{~h}$, the buffer was renewed. The $\mathrm{pH}$ mimicked the cancer environment (4.5) \& normal physiological $\mathrm{pH}$ (7.4) respectively. The buffer temperature was maintained throughout at $37^{\circ} \mathrm{C}$. At consistent time gaps of 4 , $12,24,36,48$ and $72 \mathrm{~h}, 150 \mu \mathrm{l}$ of solution was removed and renewed by same amount of fresh buffer. The drug concentrations in the NPs were estimated at $266 \mathrm{~nm}$ and were fitted to standard curve by means of UV-Vis spectroscopy. The absence of drug in the solution indicated a complete in vitro release of drug. In order to calculate the mean value, observations were made thrice.

\section{Statistical analysis}

The data was recorded as mean with standard deviation (mean $\pm \mathrm{SD}$ ) and analyzed/calculated by Origin 8 . Calculations were consummated with one-way analysis of variance (ANOVA). Statistically significant difference was pronounced with $p$ value of $<0.05$.

\section{In vitro cytotoxicity \\ Cell culture}

Nasopharyngeal carcinoma CNE-2 cell line, the folate receptor negative cells were the chosen cell line for this study. CNE-2 cells were obtained from Chinese Cell Bank of the Chinese Academy of Sciences. In an atmosphere of humidified 5\% $\mathrm{CO}_{2}$, the cells were retained in RPMI1640 medium (without folic acid) with $10 \%$ fetal bovine serum (FBS) at physiological temperature of $37{ }^{\circ} \mathrm{C}$. While the cells were growing exponentially, they were incubated and seeded on a 96 well plate at $5 \times 10^{4}$ cells $/ \mathrm{mL}$ cell density.

\section{Cytotoxicity assay}

After a cellular incubation period of $24 \mathrm{~h}$, PBS (control), $\mathrm{CuO}$ NPs, FOL-PLGA-CuO NPs, CD-1, CD-2, CD-3, free doxorubicin and docetaxel were supplemented in the cell culture at a dose of $0.1 \mathrm{mg} / \mathrm{ml}$. The dosage of $0.1 \mathrm{mg} /$ $\mathrm{ml}$ was utilized for biological formulations. At $6 \mathrm{~h}$ time interval, the medium was withdrawn followed by PBS washing of the cells. Thereafter at room temperature, to each of the well, $20 \mu \mathrm{L}$ of MTT solution $(5 \mathrm{mg} / \mathrm{mL})$ was being added after which $4 \mathrm{~h}$ incubation time was given. Once the incubation time was over, the absorbance was calculated at $492 \mathrm{~nm}$ by means of a microplate reader. The results were repeated for 5 times and articulated as mean \pm SD.

\section{Live/dead cell assay for cytotoxicity}

Cytotoxicity of the PBS (control), CuO NPs, FOL-PLGACuO NPs, CD-1, CD-2, CD-3, free doxorubicin and docetaxel were determined by live/dead cell assay. The Live/ Dead cell assay kit was procured from Thermo Fisher Scientific, China. The method monitored was as per the directives mentioned by the company. The study was done with $5 \mathrm{~mL}$ of mixture of dyes $(100 \mathrm{mg} / \mathrm{mL}$ acridine orange (AO) and $100 \mathrm{mg} / \mathrm{mL}$ Ethidium bromide, EtBr), supplemented in a $9 \mathrm{ml}$ cell suspension having concentration of $10^{5}$ cells $/ \mathrm{mL}$ on the coverslip for the microscope purposes. After incubation of 3-4 min, visualization of cells was done using a Nikon made fluorescence microscope with an excitation filter of $510-590 \mathrm{~nm}$. The procedure was adapted from Kannan (Varukattu et al. 2020) and Vivek et al. (2014).

\section{DAPI staining}

The CNE-2 cells were exposed to $\mathrm{CuO}$ NPs, FOL-PLGA$\mathrm{CuO}$ NPs, CD-1, CD-2, CD-3, free doxorubicin and docetaxel as the protocol mentioned above. The NP and drug treated cells are fixed with methanol: acetic acid $(3: 1, \mathrm{v} / \mathrm{v})$ before PBS wash. For staining the cells, $1 \mathrm{mg} / \mathrm{ml}$ DAPI was utilized and the cells were kept in dark for $30 \mathrm{~min}$. A fluorescent microscope was utilized to study the images of the cells stained with DAPI using excitation and emission wavelength of 358 and $461 \mathrm{~nm}$ respectively.

\section{Impediametric studies}

The device to measure impedance (ECIS) consisted of eight wells. Ten gold microelectrodes of $250 \mu \mathrm{m}$ diameters were present in each cell which sensed the smooth flow of current through the solution. Each well had a volume of $600 \mu \mathrm{l}$ with a substrate area of $0.8 \mathrm{~cm}^{2}$. Within a tissue culture incubator, the ECIS devices were incubated with RPMI 1640 media overnight. Confluent CNE-2 cell cultures were incubated from a cell culture mentioned above. Cells were incubated for $72 \mathrm{~h}$ and the following were added: PBS (control), $\mathrm{CuO}$ NPs, FOL-PLGA-CuO NPs, CD-1, CD-2 and CD-3 at the concentration of $0.1 \mathrm{ml}$. Incubation for $48 \mathrm{~h}$ was carried out and thereafter measurements of impedance values of the samples were carried out. The frequency range was designated from $100 \mathrm{~Hz}$ to $1 \mathrm{MHz}$ in a logarithmic scale. Consequently, ZsimpWin (Ver. 3.10) software was used to fit the impedance data. Pradhan et al. (Pradhan et al. 2014) supplied 
the equivalent circuit for the impedance measurements explained in Fig. 5. RS \& RI was the resistance of solution and charge transfer resistance respectively while CS and QM represented capacitance of water and interface impedance of cells.

\section{Statistical data analysis}

The analysis of impedance values and investigations of cell assay were done in triplets to produce reproducible data and the data were represented with their equivalent relative standard deviations (RSD).

\section{Cellular uptake of the NPs}

The procedure we adapted with modifications was of (Mo and Lim 2005) in our work. $5 \times 10^{4}$ cells $/ \mathrm{mL}$ of cell suspensions of HNE-1 and CNE- 2 were seeded in 96 well plates. Thereafter when $80 \%$ cell confluency was attained, the cells were incubated with CD-1, CD-2, CD-3, free doxorubicin and docetaxel in RPMI 1640 for $6 \mathrm{~h}$ at $37{ }^{\circ} \mathrm{C}$. Prior to incubation, docetaxel was coupled with fluorescent groups and we utilized NBD fluorophore for labelling as per the study of Dubois et al. (1995). At interval of 1 hour, for 3 times, the wells were rinsed with $0.05 \mathrm{~mL}$ of PBS with addition of $0.1 \mathrm{~mL}$ of culture medium. Afterwards, $0.05 \mathrm{~mL}$ of $0.5 \%$ triton in $0.2 \mathrm{~N} \mathrm{NaOH}$ was applied as lysing agent for all wells. The intensity of fluorescence of free doxorubicin, CD-2 and CD-3 was observed and noted with a microplate reader at excitation and emission wavelength of 552 and $575 \mathrm{~nm}$ respectively. The intensity of fluorescence of free labelled docetaxel and CD-2 was noted at excitation spectra of $295 \mathrm{~nm}$ and emission spectra of $305 \mathrm{~nm}$. The percentage of cellular uptake efficiency was deliberated according to the following formula:

$$
\begin{aligned}
& \text { Cellular uptake efficiency }(\%) \\
& \quad=\text { Fluorescent efficiency of samples } \\
& \quad \div \text { Flourescent efficiency of control } \times 100
\end{aligned}
$$

\section{Statistical data analysis}

Complete statistics in the current study were articulated as means and standard deviation (mean $\pm \mathrm{SD}$ ) and analyzed by Origin 8 \& Microsoft excel. Calculations were done using the one-way analysis of variance (ANOVA). The statistically significant difference was deliberated to be $\mathrm{p}$ value $<0.05$.

\section{Results}

\section{Physical characterization of the NPs}

The morphological analysis revealed the spherical structure of $\mathrm{CuO}$ NPs, FOL-PLGA-CuO NPs and CD-1, CD-2 and $\mathrm{CD}-3$ via SEM. The synthesized NPs had uniform size distribution. The $\mathrm{CuO}$ NPS revealed irregularities in shape and size with slightly serrated edges as may

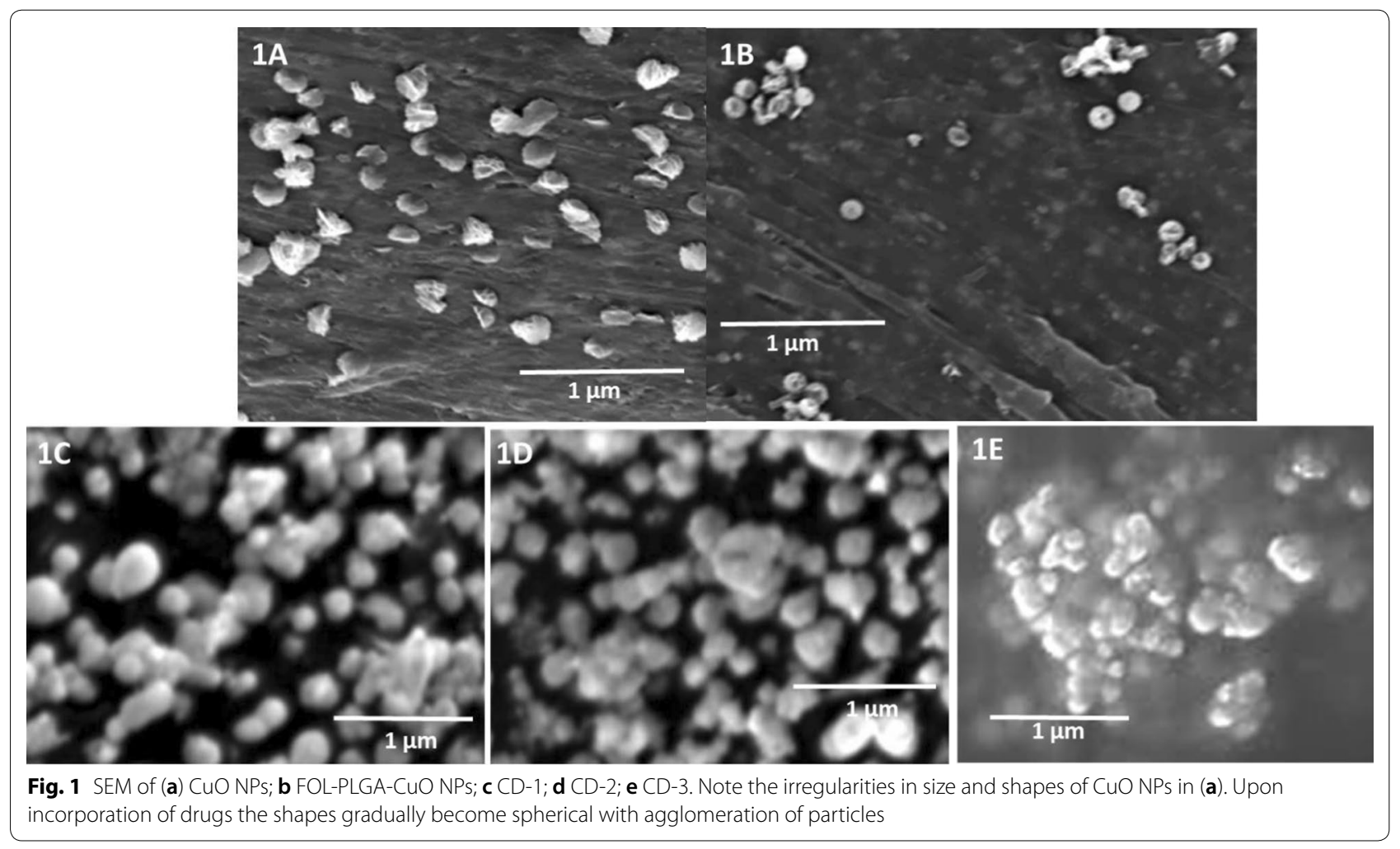


be seen in Fig. 1a while following the coating of PLGA and folic acid over $\mathrm{CuO}$ nanoparticles revealed smooth NPs in Fig. 1b. Subsequently in Fig. 1c-e, smooth NPs were observed for CD-1, CD-2 and CD-3. There was no observed agglomeration or accumulation of the NPs. Elemental $\mathrm{Cu}$ was also detected via the EDX studies as seen in Fig. 2. Furthermore, the loading of the drugs docetaxel and doxorubicin were indicated by the TEM photomicrographs in Fig. 3. TEM photomicrographs reinforced the observation made BY SEM. The coating PLGA and conjugation with folic acid also influenced the size of the NPs. It was seen that while the $\mathrm{CuO}$ NPs were in the range of $115 \mathrm{~nm}$, the size increased to $165 \mathrm{~nm}$ in case of FOL-PLGA-CuO NPs and in case of CD-1, CD-2 and D-3, the size ranged from 180 to $195 \mathrm{~nm}$. The size, PDI and zeta potential values were indicated in Table 1. The zeta potential values of uncoated $\mathrm{CuO}$ NPs had positive charge $(22.7 \mathrm{mV})$ which shifted to a negative charge on being coated with folic acid \& PLGA $(-25.7 \mathrm{mV})$ and loaded with multiple drugs $(-26.8 \mathrm{mV})$.
FTIR data (Fig. 4) of free doxorubicin exhibited peaks at $3410 \mathrm{~cm}^{-1}$ due to $\mathrm{N}-\mathrm{H}$ and $\mathrm{O}-\mathrm{H}$ stretching vibrations at $3317 \mathrm{~cm}^{-1}$ due to primary amine structure. Similarly docetaxel revealed peaks at $\mathrm{C}=\mathrm{C}$ asymmetric stretch of vibration and $\mathrm{C}=\mathrm{O}$ variable weak intensity vibration at $721 \mathrm{~cm}^{-1} \&$ strong intensity $\mathrm{C}=\mathrm{O}$ stretching vibration at $1741 \mathrm{~cm}^{-1}$. The FOL-PLGA-CuO NPs showed folic acid conjugation with PLGA by a shift in peak at asymmetric stretching vibration of $-\mathrm{NH}_{2}$ in folate corresponds to the band at $1459 \mathrm{~cm}^{-1}$ and $\mathrm{C}=\mathrm{O}$ stretching in carboxyl acids was seen at $1700 \mathrm{~cm}^{-1}$. CD-1, CD-2 and CD-3 showed shifted peaks below $3164 \mathrm{~cm}^{-1}$ caused by the drugs loaded onto NPs.

\section{Encapsulation and loading efficiency}

The \% of encapsulation and loading of drugs in CD-1, CD -2 and CD-3 were clearly denoted in Table 2 . The loading of drugs by FOL-PLGA-CuO NPs was originally swift followed by a slow decline in the loading rate leading to complete inundation. The
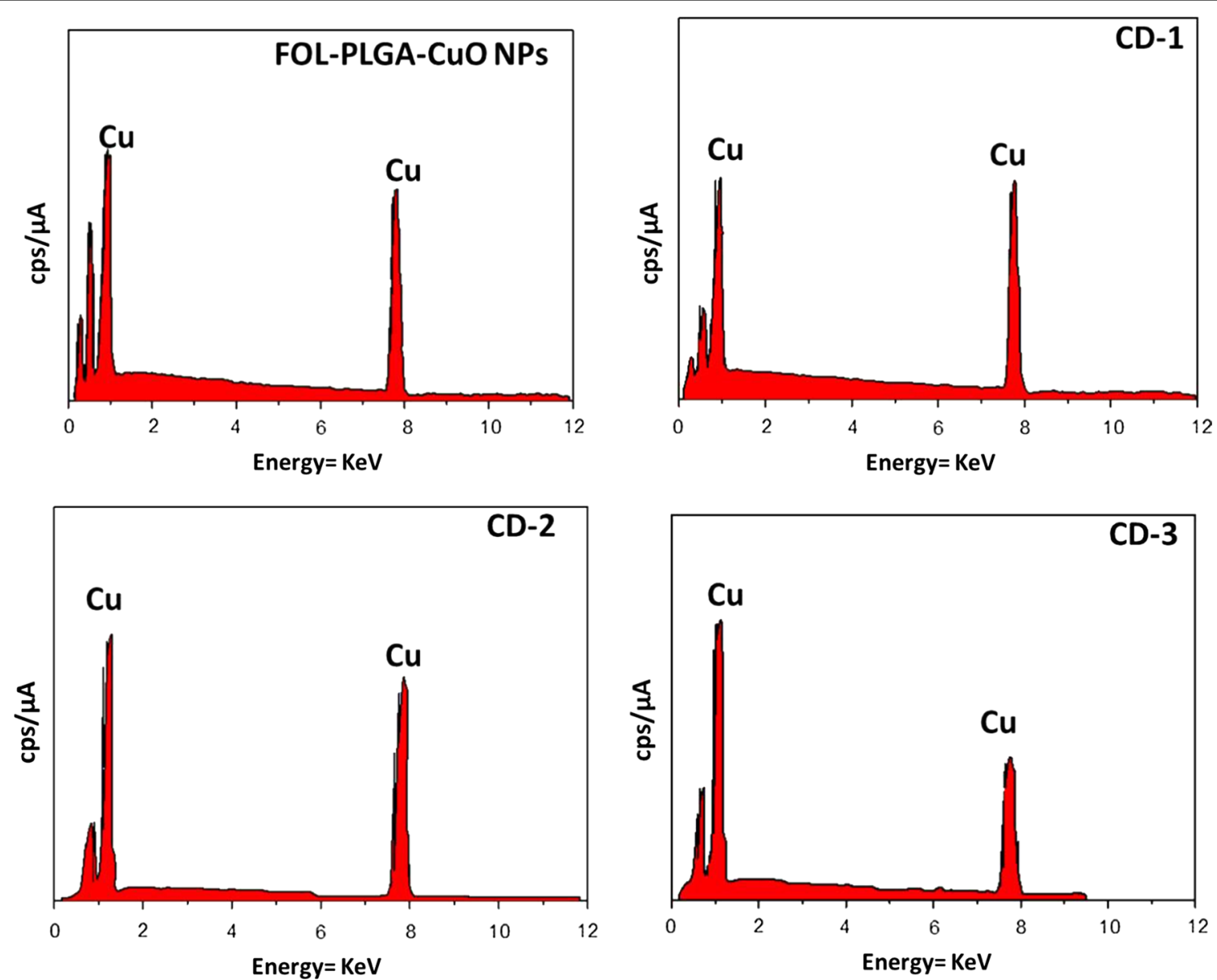

Fig. 2 Presence of elemental Cu in CUO NPs, FOL-PLGA-CUO NPs, CD-1, CD-2 and CD-3. This indicates the incorporation of drugs in CuO nanoparticles 


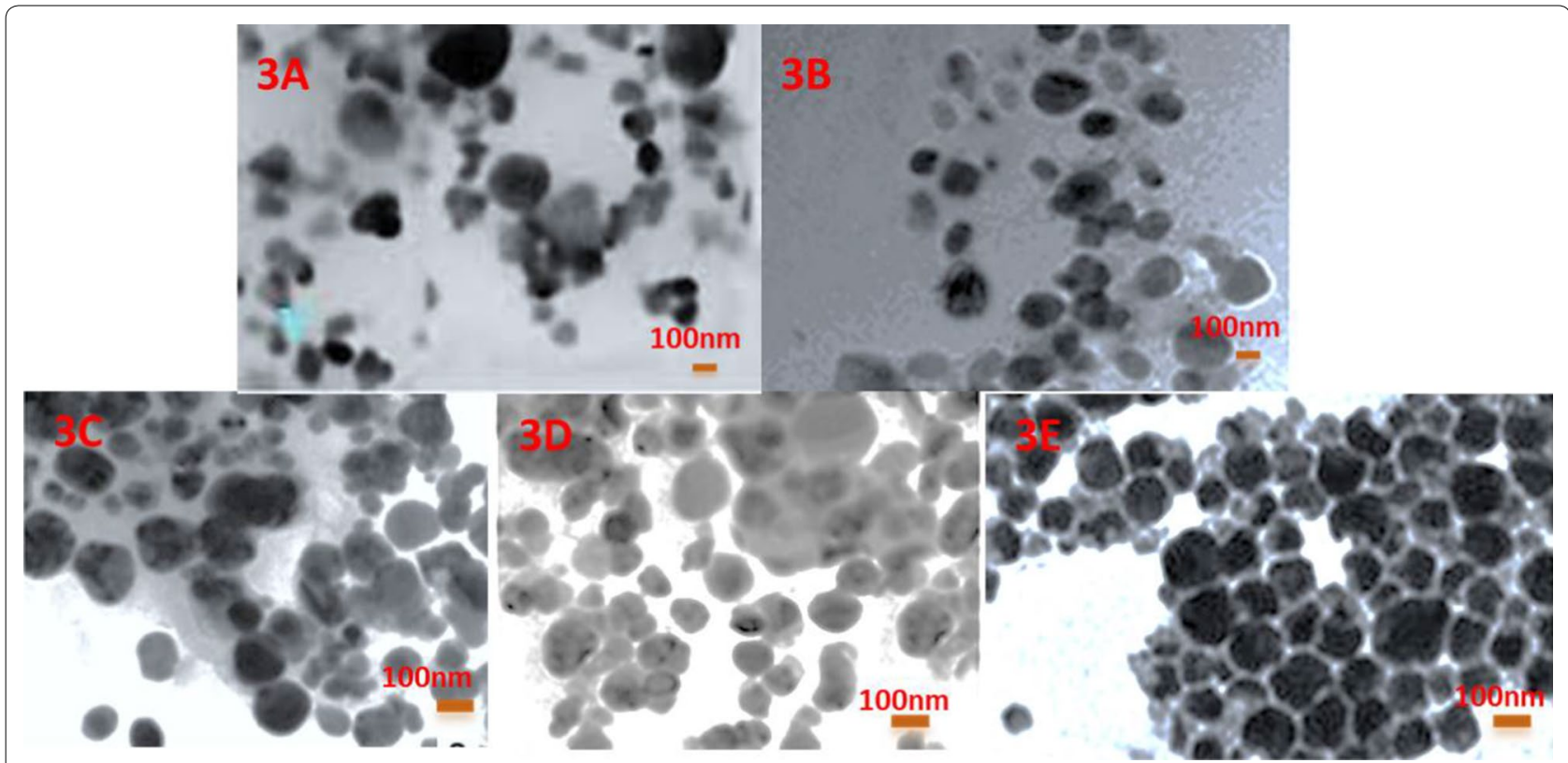

Fig. 3 TEM of (a) CUO NPs; b FOL-PLGA-CUO NPs; $\mathbf{c}$ CD-1; d CD-2; e CD-3. Similar kind of irregularities as seen in SEM are also visualized in TEM micrographs of CUO NPs

Table 1 Size distribution, zeta potential and PDI of CuO NPs, FOL-PLGA-CuO NPs and CD-1, CD-2 and CD-3

\begin{tabular}{|c|c|c|c|c|}
\hline SI. no. & & Size of nanoparticles $(\mathrm{nm})$ & Zeta potential $(\mathrm{mV})$ & $\begin{array}{l}\text { Polydispersity } \\
\text { index (PDI) }\end{array}$ \\
\hline 1. & CuO NPs & $115.24 \pm 2.3$ & $22.7 \pm 0.1$ & $0.112 \pm 0.01$ \\
\hline 2. & FOL-PLGA-CuO NPS & $164.98 \pm 1.3$ & $-25.7 \pm 0.1$ & $0.211 \pm 0.03$ \\
\hline 3. & CD-1 & $180.23 \pm 1.1$ & $-26.5 \pm 1.3$ & $0.345 \pm 0.01$ \\
\hline 4. & $C D-2$ & $195.13 \pm 1.6$ & $-26.3 \pm 0.1$ & $0.312 \pm 0.02$ \\
\hline 5. & CD-3 & $189.45 \pm 1.4$ & $-24.5 \pm 0.2$ & $0.223 \pm 0.03$ \\
\hline
\end{tabular}

Note the shift in Zeta potential from + ve in CuO NPs to -ve in rest of formulations

encapsulation efficiencies of CD-1, CD-2 and CD-3 were $70.15 \% \pm 0.41,82.15 \% \pm 1.21$ and $69.13 \% \pm 2.12$ respectively. There were noteworthy differences between the encapsulation of drug(s) in CD-1, CD-2 and CD-3 which may be related to the coating of PLGA over the nanoparticles. We will discuss this later. The drug loading efficiency CD-1, CD-2 and CD-3 were $39.5 \%, 42.45 \%$ and $34.14 \%$ respectively.

\section{Stability studies}

The stability of the CD-1, CD-2 and CD-3 is depicted in Table 3 . The size, zeta potential and PDI almost remain unchanged over a period of 30 days. No agglomeration of the NPs was observed during microscopy which was also confirmed by the stability studies. The slight changes in size may be attributed to rearrangement of the PLGA and folate on the surface of the NPS in neat and dense manner. However, a lot of factors like change in concentration of PLGA, centrifugation speed and time, $\mathrm{pH}$ may contribute for NPs stability.

\section{In vitro release studies}

In vitro release studies were a big revelation for the percentage of PLGA to be utilized as coating over the surface of multiple drug loaded NPs as seen in Fig. 5a and b. It was observed in $\mathrm{pH} 4.5$ that with $\mathrm{CD}-1$ coating the release of the drugs from the NPs was fast and unhindered for $15 \mathrm{~h}$. However it was observed that after $15 \mathrm{~h}$ the drug release from the NPs was slow and depleted within $25 \mathrm{~h}$ whereas in case of CD-2 coating of PLGA, the drug released continued in a slow and sustained manner up to $50 \mathrm{~h}$. However, the important point was to note that in CD-3 coating of PLGA, the drug release was slow from the beginning and continued insignificant amounts most of the time which finally stopped altogether after $30 \mathrm{~h}$. 


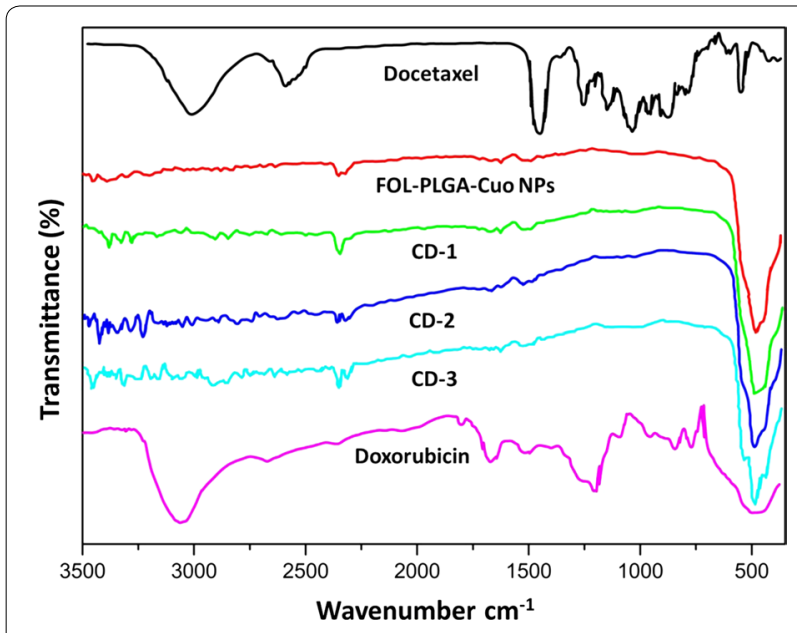

Fig. 4 FTIR Spectra of free docetaxel, doxorubicin, CuO NPS, FOL-PLGA-CuO NPS, CD-1, CD-2 and CD-3. No new or drastic changes are seen in the spectra of CD-1, CD-2 or CD-3 which may indicate a change in function

Table 2 Encapsulation efficiency (EE \%) and loading efficiency (LE \%) of CuO NPs, FOL-PLGA-CuO NPs and CD-1, CD-2 and CD-3 NPs

\begin{tabular}{|c|c|c|c|}
\hline SI. No. & & $\mathrm{EE} \%$ & LE\% \\
\hline 1. & CD-1 & $70.15 \pm 0.41$ & $39.5 \pm 2.23$ \\
\hline 2. & CD-2 & $82.15 \pm 1.21$ & $42.25 \pm 1.34$ \\
\hline 3. & CD-3 & $69.25 \pm 2.12$ & $34.14 \pm 2.31$ \\
\hline
\end{tabular}

This was an extremely significant revelation. In $\mathrm{pH}$ 7.4, it was seen that for CD-1, the drug release was slow, in small spells for about $10 \mathrm{~h}$ only. For CD-2 it was slow and sustained for about $36 \mathrm{~h}$ and for CD-3, it was extremely less amount for $20 \mathrm{~h}$ only. It would be important to mention that $\mathrm{pH} 4.5$ mimicked the tumor microenvironment whereas $\mathrm{pH} 7.4$ mimicked normal physiological environment.

\section{Cytotoxicity studies}

As may be observed, a detailed cytotoxicity study of the PBS (control), prepared CuO NPs, FOL-PLGA-CuO NPs, CD-1, CD-2 and CD-3 NPs was executed utilizing MTT assay, $\mathrm{AO} / \mathrm{EtBr}$ staining and DAPI staining of $\mathrm{CNE}-2$ cells. It was seen that cells were cytotoxic in a \% coating of PLGA dependent manner. The $\mathrm{IC}_{50}$ was obtained to be $\sim 30 \mu \mathrm{g} / \mathrm{ml}$ for $48 \mathrm{~h}$ in CD-2, $27 \mu \mathrm{g} / \mathrm{ml}$ for $48 \mathrm{~h}$ in CD-3 and $22 \mu \mathrm{g} / \mathrm{ml}$ in CD-1. The CuO NPs were extremely cytotoxic and the viability of the cells decreased to $21 \%$ whereas in FOL-PLGA- CuO NPs the viability increased to $90 \%$. On treatment with PBS, the cell viability was $97 \%$ as expected. In CD-1, CD-2 and CD-3, the cell viability was $72 \%, 83 \%$ and $69 \%$ respectively. The cells treated with PBS exhibited $90 \%$ viability. This was clearly exhibited in Fig. 6.

The $\mathrm{AO} / \mathrm{EtBr}$ reinforced the MTT assay results in Fig. 7. The photomicrographs revealed that the cells exposed to $\mathrm{CuO}$ NPs exhibited reduced cell size, dead cells, pcknosis, karyorrhexis which suggested the potent cytotoxic effect. There were also images of cell membrane blebbing and shrinkage of cells (Hengartner 2000). Uniform cells were observed in those treated with FOLPLGA $\mathrm{CuO}$ NPs indicating much reduction of cytotoxicity of the NPs. There was decrease in the number of viable cells as indicated by green colour due to penetrability of AO in the samples treated with CD-1 which may be due to the uninhibited release of drug. The dead cells were indicated by red colour due to penetrability of both $\mathrm{AO}$ and EtBr. CD-2 \& CD-3 exhibited maximum number of viable cells. The cells that were treated with CD-1, CD-2 \& CD-3 did not depict any sort of damaged/ destroyed cells or cell debris which may be an indication of reduction of cytotoxicity.

DAPI staining revealed a similar trend too in Fig. 8. DAPI is DNA binding nuclear cell stain which helped in identification of necrotic and live cells. Normal morphology of cells was perceived $\mathrm{n}$ treatment with PBS and FOL-PLGA-CuO NPs. The cells treated with $\mathrm{CuO}$ NPs revealed cellular suicide with prominent cell shrinkage, breaking and death. However upon treatment with CD-1, CD-2 and CD-3 showed limited cell deformations or death. Also, no loss of viability was evident.

Table 3 Size, zeta potential and PDI of CD-1, CD-2 \& CD-3 after 10, 20 and 30 days during stability studies

\begin{tabular}{|c|c|c|c|c|c|c|c|c|c|}
\hline & \multicolumn{3}{|l|}{ CD-1 } & \multicolumn{3}{|l|}{ CD-2 } & \multicolumn{3}{|l|}{ CD-3 } \\
\hline & Size $(\mathrm{nm})$ & $\begin{array}{l}\text { Zeta potential } \\
(\mathrm{mV})\end{array}$ & PDI & Size $(\mathrm{nm})$ & $\begin{array}{l}\text { Zeta potential } \\
(\mathrm{mV})\end{array}$ & PDI & Size (nm) & $\begin{array}{l}\text { Zeta potential } \\
(\mathrm{mV})\end{array}$ & PDI \\
\hline 10 days & $181.23 \pm 1.1$ & $-26.5 \pm 1.3$ & $0.345 \pm 0.03$ & $196.13 \pm 1.6$ & $-26.3 \pm 0.1$ & $0.311 \pm 0.02$ & $190.13 \pm 0.4$ & $-23.2 \pm 0.2$ & $0.221 \pm 0.03$ \\
\hline 20 days & $183.22 \pm 1.3$ & $-24.3 \pm 1.2$ & $0.322 \pm 0.04$ & $197.33 \pm 1.4$ & $-24.1 \pm 0.3$ & $0.310 \pm 0.01$ & $191.45 \pm 1.3$ & $-22.6 \pm 0.1$ & $0.218 \pm 0.01$ \\
\hline 30 days & $184.3 \pm 1.1$ & $-23.5 \pm 0.3$ & $0.311 \pm 0.01$ & $198.13 \pm 0.2$ & $-22.3 \pm 0.5$ & $0.308 \pm 0.03$ & $192.15 \pm 1.4$ & $-21.3 \pm 0.3$ & $0.217 \pm 0.02$ \\
\hline
\end{tabular}



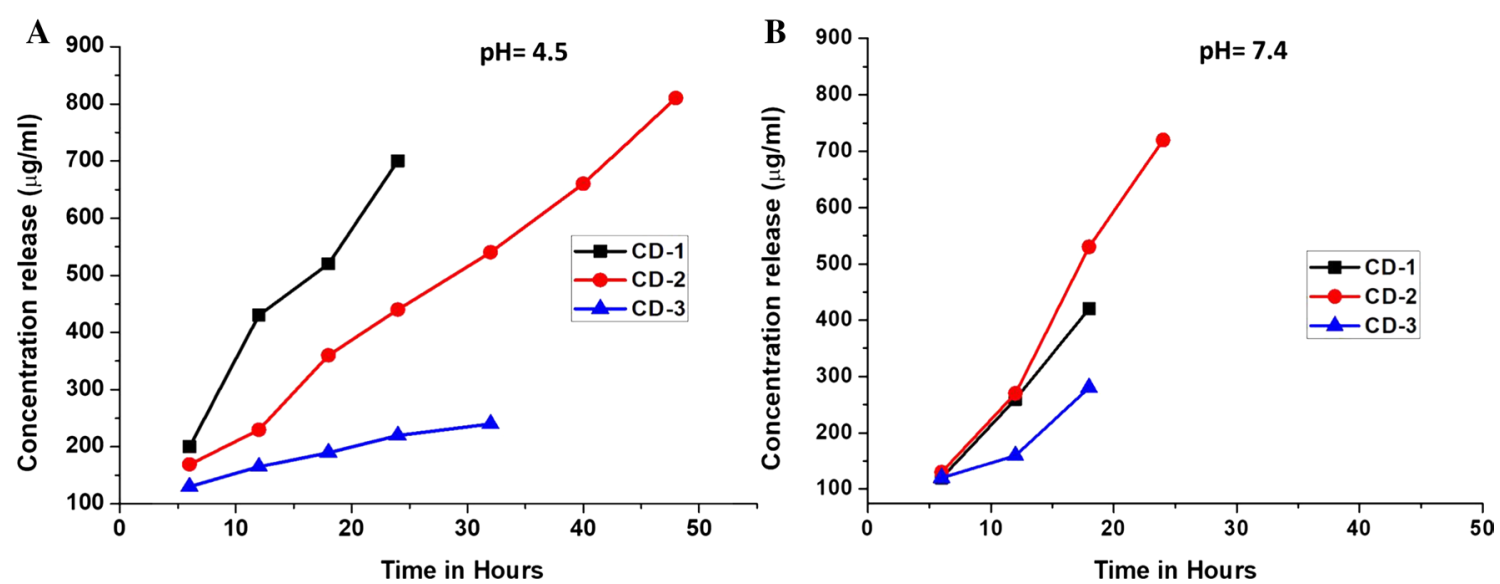

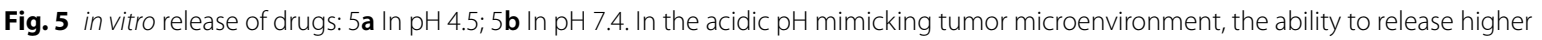
amounts of drugs is seen for longer spell of time by CD-3

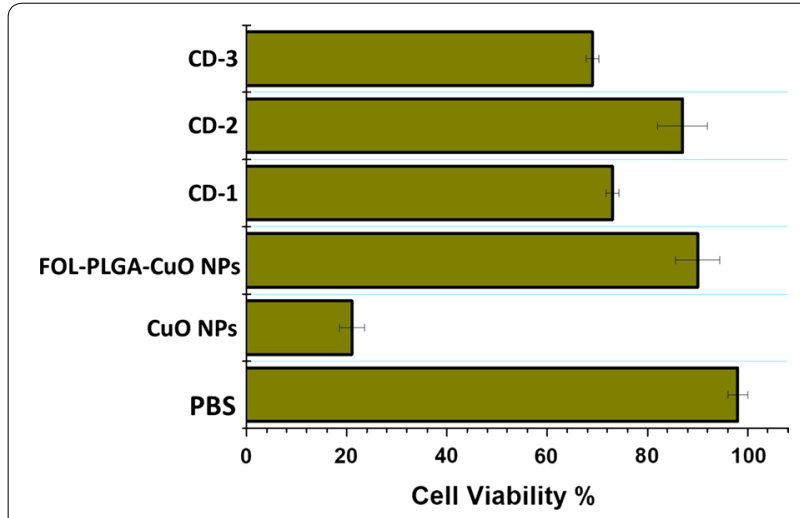

Fig. 6 Cytotoxicity of PBS, CuO NPs, FOL-PLGA-CuO NPS, CD-1, CD-2 $\&$ CD-3. The cytotoxicity of CD-3 is quite reduced

\section{Impediametric studies}

CNE-2 cells were chosen because of absence of folate receptor which may be equated to normal cells, plus they were easily cultured with proper documentation. Here we had purposefully chosen CNE-2 cells to view how the absence of folate receptors may affect the endocytosis-mediated delivery of NP formulations to targeted tissue. We theorized that progression of growth in cells of the CNE-2 will increase the cellular metabolism because of which there will be adequate cellular metabolism by-products which were extremely conductive in nature and may aid in decreasing impedance. We also assumed that the cytotoxic formulations may retard the growth of cells, thereby increasing

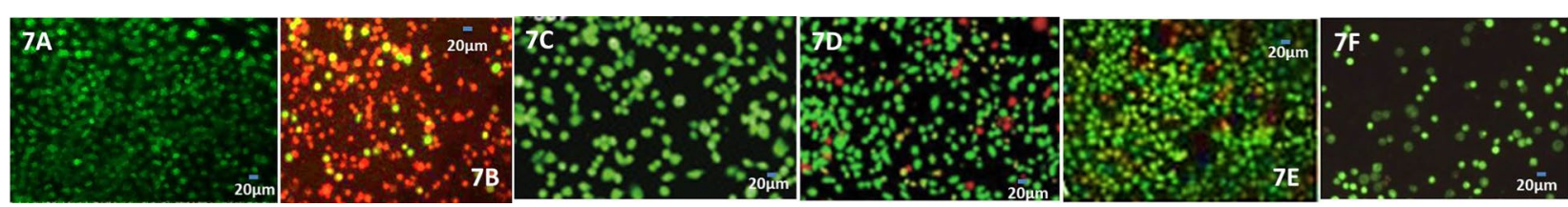

Fig. 7 Live dead assay of CNE-2 cells on treatment with (a) PBS; b CuO NPs; c FOL-PLGA-CuO NPs; $\mathbf{d}$ CD-1; e CD-2; f CD-3. Note the reduced cell size and huge number of dead cells in (b) indicating potent cytotoxic effects much reduced in other formulations
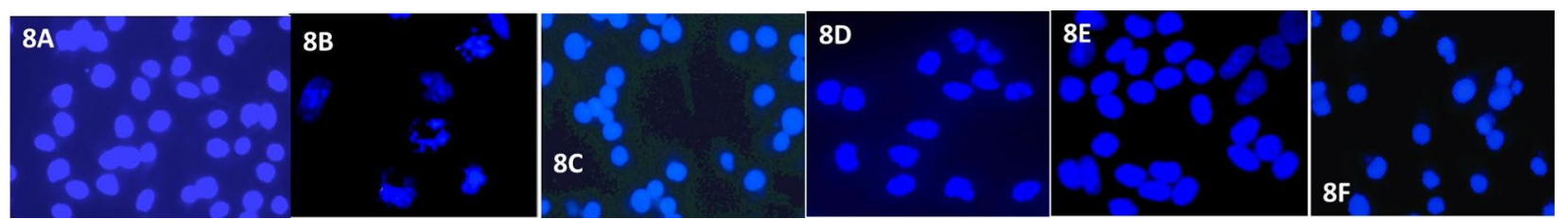

Fig. 8 DAPI staining of CNE-2 cells on treatment with (a) PBS; b CUO NPs; $\mathbf{c}$ FOL-PLGA-CUO NPs; $\mathbf{d}$ CD-1; e CD-2; f CD-3. DAPI staining of cells treated with $\mathrm{CuO}$ nanoparticles show dead and disfigured cells not visible in other formulations 


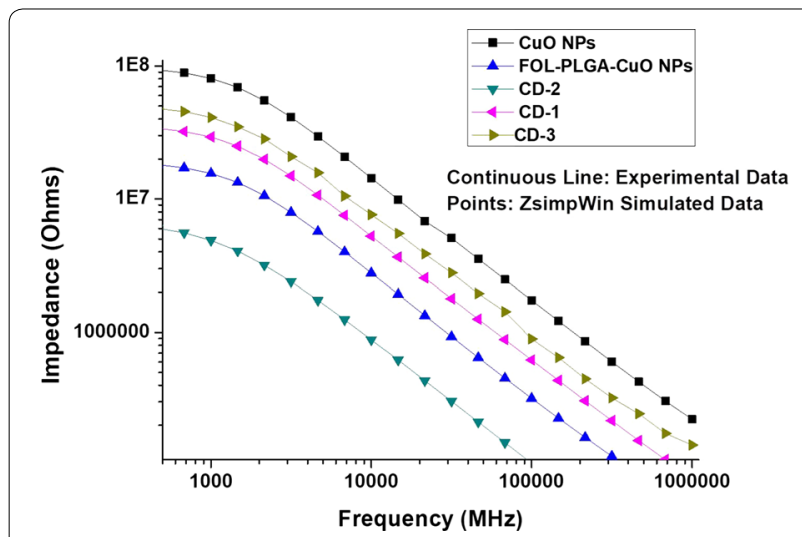

Fig. 9 Impedance values of CNE-2 cells on treatment with CuO NPs, FOL-PLGA-CuO NPs, CD-1, CD-2 \& CD-3

impedance. It was clearly seen in Fig. 9 from the bode plot, that $\mathrm{CuO}$ NPs being the most cytotoxic there was increase in impedance and FOL-PLGA-CuO NPs along CD2 \& CD-3 having least impedance values. CD-2 and CD-3 despite the drug release, offered least resistance to the growth of cells at lower frequency of $100 \mathrm{~Hz}$. However, there is a decrease in the phase angle value up to $1 \mathrm{kHz}$ and formation of plateau in the range of frequency from 1 to $10 \mathrm{kHz}$ and then steady increase till $1 \mathrm{MHz}$. However at higher frequencies $(4000 \mathrm{~Hz})$, since current directly passes through the medium, the impedances dropped down. It was also proved that $\mathrm{CuO}$ NPs offer most resistance to the growth of CNE-2 cells owing to their cytotoxicity which was much reduced in PLGA-CuO NPs along CD2 \& CD-3. It is an altogether different outlook in CD-1. Owing to a thin layer of PLGA coating and unhindered drug release, the impedance was low but still more than $\mathrm{CuO}$ NPs. However at higher frequencies, there was a dip in impedance values too.

\section{Cellular uptake studies}

Efficiency of cellular uptake of the NPs was an important dynamics for their synthesis. It was important to deliver the multiple drugs to the targeted tissue; hence two different nasopharyngeal cell carcinoma lines were designated for the study, folate positive (HNE-1) cells and folate receptor negative (CNE-2) cells. Figure $10 \mathrm{dem}$ onstrates the efficiency of cellular uptake of free doxorubicin, docetaxel, CD-1, CD-2 and CD-3. The free drug concentration was adjusted with the concentration of the drug in the NPs which was $1 \mathrm{mg} / \mathrm{ml}$. Uptake of free doxorubicin and free labelled docetaxel by cells was consistently less than NPs in both cell lines. The HNE-1 uptake efficiency of free doxorubicin was 53\%, docetaxel was $60 \%$ and CD- 1 was $79 \%$, CD-2 was $83 \%$ and CD-3 was $72 \%$ respectively. However when compared, the uptake of free doxorubicin, docetaxel and NPs in CNE-2 was significantly less than that of HNE-1. The CNE-2 uptake efficiency of free doxorubicin was $44 \%$, docetaxel was $46 \%$ and CD- 1 was $62 \%, \mathrm{CD}-2$ was $68 \%$ and CD-3 was $57 \%$ respectively. This may be accounted by the presence of folate receptors in the HNE-1 cells which triggers more cellular uptake of NPS that possess the folate ions.

\section{Discussion}

A complete assessment of the physical and chemical characteristics of the synthesized NPs, that encompassed size, morphological analysis, structural \& surface modifications along with coatings which resulted during the

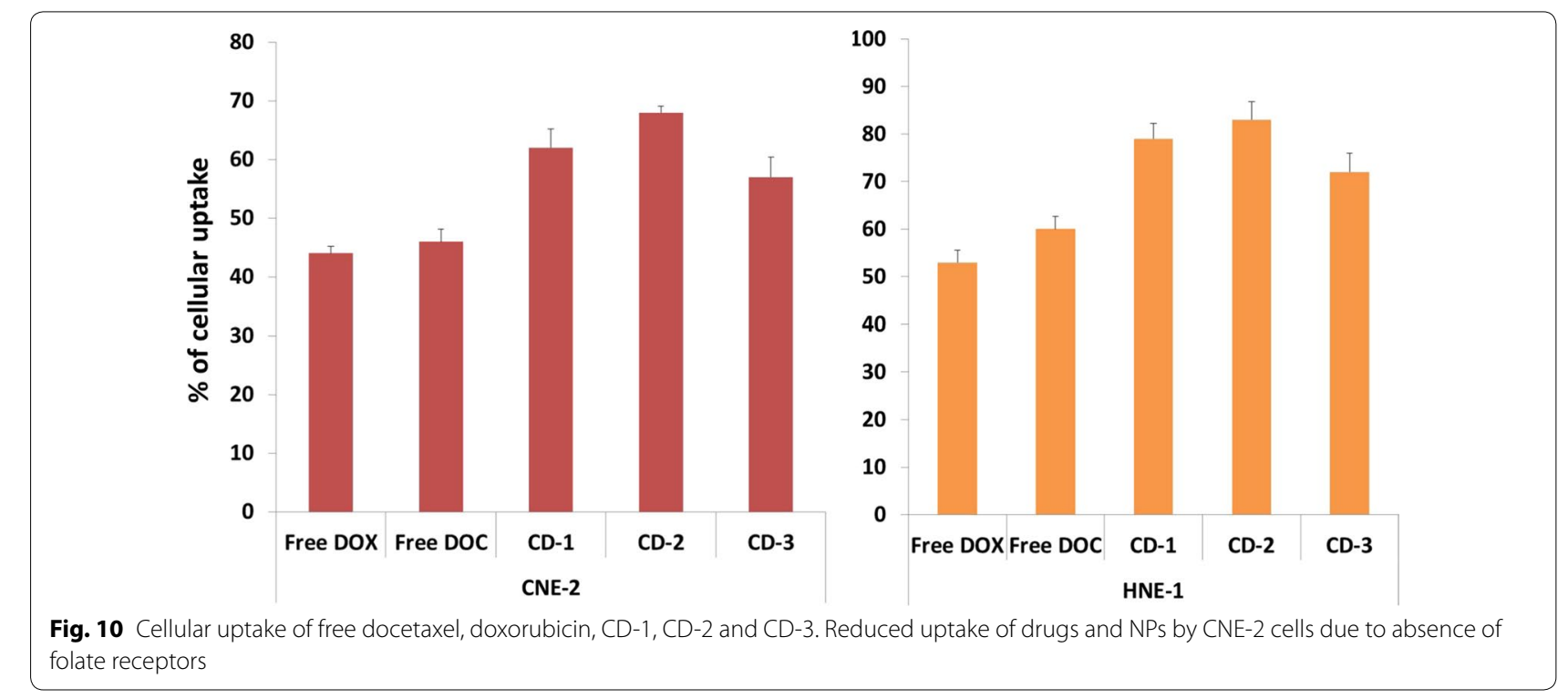


various synthesis techniques applied, needed to be analysed. Understanding this with the context of biology is essential to advance the pre-existing techniques which may need to undergo a complete transformation. There is an emerging need for development of new assays along with modification of the existing to suit appropriate control on quality assurance both at the theoretical research and contrived manufacturing production levels (Hussain et al. 2009). CuO NPs are usually known to be broad spectrum biocides which were known for their effectiveness against, bacteria, fungi and algae (Jia et al. 2012). But, despite being excellent microbicides, it had been reported widely that nanosized $\mathrm{Cu}$ generated greater cytotoxicity in cell lines and caused extensive damage (Sun et al. 2012).

Therefore, main challenge of our study involved minimizing the cytotoxicity of $\mathrm{CuO}$ NPs. The resolution of our study was to minimize $\mathrm{CuO}$ NPs cytotoxicity which otherwise are also excellent nanocarriers of drug to a particular targeted tissue. Hence after providing a coating of PLGA at different concentrations $(0.5 \%, 1 \%, 1.5 \%)$, the characterization of NPs was carried out to predict the cytotoxicity albeit it was complex phenomena. The preparation of $\mathrm{CuO}$ nanoparticles in Milli- $\mathrm{Q}$ water rather than ethylene glycol or mixture of ethylene glycol/water may be conceptualized as one of the best methods of synthesis of the NPs (Kamalgharibi et al. 2016). It can be noted that the toxicological impact of nanomaterials varies from size and mode of fabrication, both in vitro and in vivo (Ranjan et al. 2020a; Ranjan et al. 2020b; Kumar et al. 2020; Dasgupta et al. 2019; Ranjan et al. 2019; Dasgupta et al. 2018; Ranjan et al. 2018; Aditi et al. 2018; Ranjan and Chidambaram 2016a; Dasgupta and Chidambaram 2016; Ranjan et al. 2016a; Dasgupta et al. 2016a; Ranjan et al. 2016b; Dasgupta et al. 2016b; Saxena et al. 2020).

In order to minimize the cytotoxicity of $\mathrm{CuO}$ NPs, the characterization of these may a significant role. For example, the size of the nanoparticles is an important consideration for toxicity studies. Numerous particle properties like surface reactivity and toxicity are derivatives of particle size of NPs. Particles with smaller size ensure a larger surface area-to-volume ratio when equated with bigger sized particles, and the particle numbers in a given mass is considerably increased. It has been assumed unanimously that NPs are known to possess more cytotoxicity than their larger counterparts. However, the relationship between physical characteristics of NPs and their toxicity goes way beyond that.

Any polymer-drug interaction is well represented by the FTIR data which in this case is descriptive in nature. After comparison of the free doxorubicin, docetaxel, $\mathrm{CuO}$ NPs, FOL-PLGA-CuO NPs, CD-1, CD-2 and CD-3
FTIR data, it was concluded that there was no changes in the structure of the drugs during encapsulation which may affect their efficiency as anticancer agents. There was no indication of loss of functional peaks or major shift in peaks. The negative zeta potential obtained in case of FOL-PLGA-CuO NPs, CD-1, CD-2 and CD-3 as against positive charge of $\mathrm{CuO}$ may led us to believe that negatively charged particles bind to the cationic sites of cells and may be the reason of higher cellular uptake.

Encapsulation and loading efficiency led us to conclude that the amount of PLGA used in the synthesis of NPs plays a significant part in the adsorption of docetaxel and doxorubicin. The coating probably prevented any leaching of drugs from the nanoparticles in case of CD-2 NPs. Where the coating in CD-1 was too thin to interrupt the uninhibited drug flow, in CD-3, the coating of 5\% PLGA may be a hindrance to drug release for functionality as showed by the in vitro drug release experiments. $\mathrm{pH}$ also formed an important factor for the in vitro release of drugs. The ability to release higher amounts of drugs at $\mathrm{pH}$ mimicking tumor microenvironment was added as a favourable factor.

Cytotoxicity studies which were the prime goal of the current research were done in detail with different kind of staining procedures $(\mathrm{AO} / \mathrm{EtBr} \& \mathrm{DAPI})$. The cytotoxic effect of $\mathrm{CuO}$ nanoparticles were evidently seen in cell damage. However, the effect was much reduced after the three different concentration of PLGA coating was done. This may be indicative that the coating prevents the leaching of free copper ions in the cells which may cause the damage. The folate conjugation also improved the targeted drug delivery which is why the NPs were effectively taken up the HNE-1 cells. The cellular uptake studies also indicated that the folate conjugated with the receptors on the cellular surface and the intake of drugs may be carried out by the process of endocytosis.

The impediametric studies were also carried out to reinforce the cytotoxicity studies. The magnitude of impedance decreases progressively with frequency increase. This early disparity of slope at lower frequency range is because of the increased drug-cell interactions which leads to death of cells and hence their non-attachment from the surfaces of the electrode. The relative standard deviations (RSD) for different designs in experiment for cells treated with different drug concentration and untreated samples result below $10 \%$ which exhibited that the fabricated impedance biosensor devices are completely reproducible without errors. Hence it may, safely be concluded that the FOL-PLGA-CuO NPs, CD-1, CD-2 \& CD-3 significantly deliver multiple drugs to the targeted cells without being acutely toxic to the normal/ surrounding cells. 
For designing an effective nanodrug carrier, one has to be categorically crucial to target cancer cells in addition to minimal toxicity toward the normal cells. CuO NPs as nanocarriers for multiple chemotherapeutic drug delivery to targeted tissue have garnered much consideration due to the theory that they escalate drug uptake by the cells via endocytosis by rather cancer cells than normal cells. However, cytotoxicity was a major concern for the use of $\mathrm{CuO}$ nanoparticles as nanovehicles for drug. In our study, we have loaded two potent anticancer drugs within $\mathrm{CuO}$ NPs in a two-step synthesis, and coated the NPs with PLGA followed by conjugation with folic acid to ensure greater targeting. A detailed characterization of the prepared nanoparticles was carried out to ensure reproducibility of the NPs or furthering the studies. The preparation of a cytocompatible $\mathrm{CuO}$ nanocarrier may encourage further in vitro and in vivo studies opening new pathways for transition of laboratory work to preclinical bench studies. Finally, it may be said that the study of this kind may be highlighted to minimalize the cytotoxic effect of $\mathrm{CuO}$ NPs on normal cells and consequently the health disorders that is tagged along. Our study sheds light on preparation of biocompatible $\mathrm{CuO}$ NPs for further pharmacological applications.

\section{Authors' contributions \\ Conceptualization: BZ. Data curation: L-MG. Formal analysis: BZ. Methodology: ZB, X-MX. Software: DZ. Validation: DZ, L-MG. Investigation: BZ, X-GC; Writing- review \& editing: $B Z, X-M X$ All authors read and approved the final manuscript.}

\section{Competing interests}

The authors declare no conflicts of interests.

Received: 14 July 2020 Accepted: 21 August 2020

Published online: 03 September 2020

\section{References}

Aditi J, Ranjan S, Dasgupta N, Chidambaram R (2018) Nanomaterials in food and Agriculture: an overview on their safety concerns and regulatory issues. Crit Rev Food Sci Nutr 58:297-317. https://doi.org/10.1080/10408 398.2016.1160363

Ahamed M, Akhtar MJ, Alhadlaq HA, Alrokayan SA (2015) Assessment of the lung toxicity of copper oxide nanoparticles: current status. Nanomed Nanotechnol Biol Med 10(15):2365-2377

Chang H, Jwo C, Lo C, Tsung T, Kao M, Lin H (2005) Rheology of CuO nanoparticle suspension prepared by ASNSS. Rev Adv Mater Sci 10(2):128-132

Chang Y-N, Zhang M, Xia L, Zhang J, Xing G (2012) The toxic effects and mechanisms of CuO and ZnO nanoparticles. Materials 5(12):2850-2871

Chua ML, Wee JT, Hui EP, Chan AT (2016) Nasopharyngeal carcinoma. Lancet 387(10022):1012-1024

Chusuei CC, Wu C-H, Mallavarapu S, Hou FYS, Hsu C-M, Winiarz JG, Aronstam RS, Huang Y-W (2013) Cytotoxicity in the age of nano: the role of fourth period transition metal oxide nanoparticle physicochemical properties. Chem Biol Interact 206(2):319-326

Dasgupta N, Chidambaram R (2016) Silver nanoparticle antimicrobial activity explained by membrane rupture and reactive oxygen generation. Environ Chem Lett 14(4):477-485. https://doi.org/10.1007/s10311-016-0583-1

Dasgupta N, Ranjan S, Patra D, Srivastava P, Kumar A, Ramalingam C (2016a) Bovine serum albumin interacts with silver nanoparticles with a "side-on" or "end on" conformation. Chemico Biol Interact 253:100-111. https://doi. org/10.1016/j.cbi.2016.05.018

Dasgupta N, Ranjan S, Bhavapriya R, Venkatraman M, Chidambaram R, Avadhani GS, Ashutosh K (2016b) Thermal co-reduction approach to vary size of silver nanoparticle: its microbial and cellular toxicology. Environ Sci Pollut Res 23:4149-4163. https://doi.org/10.1007/s11356-015-4570-z

Dasgupta N, Ranjan S, Debasish M, Chidambaram R (2018) Thermal Coreduction engineered silver nanoparticles induce oxidative cell damage in human colon cancer cells through inhibition of reduced glutathione and induction of mitochondria-involved apoptosis. Chem Biol Interact 295:109-118. https://doi.org/10.1016/j.cbi.2018.07.028

Dasgupta N, Ranjan S, Ramalingam C (2019) Silver nanoparticles engineered by thermal co-reduction approach induces liver damage in wistar rats: acute and sub-chronic toxicity analysis. Biotech 9:125. https://doi. org/10.1007/s13205-019-1651-6

Davis ME, Chen Z, Shin DM (2010) Nanoparticle therapeutics: an emerging treatment modality for cancer. Nanoscience and technology: a collection of reviews from nature journals, edn. World Scientific, Singapore, pp 239-250

Dubois J, Le Goff M-T, Guittritte-Voegelein F, Guenard D, Tollon Y, Wright M (1995) Fluorescent and biotinylated analogues of docetaxel: synthesis and biological evaluation. Bioorg Med Chem 3(10):1357-1368

Hengartner MO (2000) The biochemistry of apoptosis. Nature 407(6805):770-776

Hussain SM, Braydich-Stolle LK, Schrand AM, Murdock RC, Yu KO, Mattie DM, Schlager JJ, Terrones M (2009) Toxicity evaluation for safe use of nanomaterials: recent achievements and technical challenges. Adv Mater 21(16):1549-1559

Jia B, Mei Y, Cheng L, Zhou J, Zhang L (2012) Preparation of copper nanoparticles coated cellulose films with antibacterial properties through one-step reduction. ACS Appl Mater Interfaces 4(6):2897-2902

Jiang W, Kim BY, Rutka JT, Chan WC (2008) Nanoparticle-mediated cellular response is size-dependent. Nat Nanotechnol 3(3):145-150

Kamalgharibi M, Hormozi F, Zamzamian SAH, Sarafraz M (2016) Experimental studies on the stability of CuO nanoparticles dispersed in different base fluids: influence of stirring, sonication and surface active agents. Heat Mass Transf 52(1):55-62

Khoshgard K, Hashemi B, Arbabi A, Rasaee MJ, Soleimani M (2014) Radiosensitization effect of folate-conjugated gold nanoparticles on HeLa cancer cells under orthovoltage superficial radiotherapy techniques. Phys Med Biol 59(9):2249

Kumar R, Aadil KR, Ranjan S, Kumar VB (2020) Advances of nanotechnology and nanomaterials based strategies for neural tissue engineering. J Drug Delivery Sci Technol 57:101617. https://doi.org/10.1016/j.jddst 2020.101617

Lam K-O, Lee AW, Choi C-W, Sze HC, Zietman AL, Hopkins Kl, Rosenblatt E (2016) Global pattern of nasopharyngeal cancer: correlation of outcome with access to radiation therapy. Int J Radiation Oncol Biol Phys 94(5):1106-1112

Madl AK, Pinkerton KE (2009) Health effects of inhaled engineered and incidental nanoparticles. Crit Rev Toxicol 39(8):629-658

Magaye R, Zhao J (2012) Recent progress in studies of metallic nickel and nickel-based nanoparticles' genotoxicity and carcinogenicity. Environ Toxicol Pharmacol 34(3):644-650

Majumder S, Das N, Pandey N, Srivastava T, Ghosha D (2018) Synthesis, characterization of novel PLGA Encapsulated Indole Nanoparticles and Study of its cytotoxic potential against A549 lung cancer cell line. J Appl Pharm Sci 8(08):144-150

Malamatari M, Somavarapu S, Bloxham M, Buckton G (2015) Nanoparticle agglomerates of indomethacin: the role of poloxamers and matrix former on their dissolution and aerosolisation efficiency. Int J Pharm 495(1):516-526

Mo Y, Lim L-Y (2005) Paclitaxel-loaded PLGA nanoparticles: potentiation of anticancer activity by surface conjugation with wheat germ agglutinin. J Control Release 108(2-3):244-262

Nobili S, Landini I, Giglioni B, Mini E (2006) Pharmacological strategies for overcoming multidrug resistance. Curr Drug Targets 7(7):861-879

Pradhan R, Rajput S, Mandal M, Mitra A, Das S (2014) Electric cell-substrate impedance sensing technique to monitor cellular behaviours of cancer cells. RSC Adv 4(19):9432-9438 
Ranjan S, Chidambaram R (2016) Titanium dioxide nanoparticles induce bacterial membrane rupture by reactive oxygen species generation. Environ Chem Lett 14(4):487-494. https://doi.org/10.1007/s10311-016-0586-y

Ranjan S, Dasgupta N, Srivastava P, Chidambaram R (2016a) A spectroscopic study on interaction between bovine serum albumin and titanium dioxide nanoparticle synthesized from microwave-assisted hybrid chemical approach. J Photochem Photobiol, B 161:472-481. https://doi. org/10.1016/j.jphotobiol.2016.06.015

Ranjan S, Dasgupta N, Bhavapriya R, Ganesh SA, Chidambaram R, Ashutosh K (2016b) Microwave-irradiation-assisted hybrid chemical approach for titanium dioxide nanoparticle synthesis: microbial and cytotoxicological evaluation. Environ Sci Pollut Res 23:12287-12302. https://doi. org/10.1007/s11356-016-6440-8

Ranjan S, Dasgupta N, Sudandiradoss C, Ramalingam C, Kumar A (2018) Titanium dioxide nanoparticle-protein interaction explained by docking approach. Int J Nanomed 13:47-50. https://doi.org/10.2147/IJN.S125008

Ranjan S, Dasgupta N, Singh S, Gandhi M (2019) Toxicity and regulations of food nanomaterials. Environ Chem Lett 17(2):929-944. https://doi. org/10.1007/s10311-018-00851-z

Ranjan S, Dasgupta N, Mishra D, Ramalingam C (2020a) Involvement of Bcl-2 activation and $\mathrm{G} 1$ cell cycle arrest induced by hybrid approach synthesized titanium dioxide nanoparticles in colon cancer cells. Front Bioeng Biotechnol 8:606. https://doi.org/10.3389/fbioe.2020.00606

Ranjan S, Dasgupta N, Verma P, Ramalingam C (2020b) Acute and sub-chronic toxicity of titanium dioxide nanoparticles synthesized by microwaveirradiation-assisted hybrid chemical approach. J Indian Chem Soc 97:483-491

Samadian H, Hosseini-Nami S, Kamrava SK, Ghaznavi H, Shakeri-Zadeh A (2016) Folate-conjugated gold nanoparticle as a new nanoplatform for targeted cancer therapy. J Cancer Res Clin Oncol 142(11):2217-2229

Saxena P, Sangela V, Ranjan S, Dutta V, Dasgupta N, Phulwaria M, Rathore D (2020) Aquatic nanotoxicology: impact of carbon nanomaterials on algal flora. Energy Ecol Environ. https://doi.org/10.1007/s40974-020-00151-9

Sharma H, Kumar K, Choudhary C, Mishra PK, Vaidya B (2016) Development and characterization of metal oxide nanoparticles for the delivery of anticancer drug. Artificial Cells Nanomed Biotechnol 44(2):672-679

Sobin LH (1991) Histological typing of salivary gland tumours. Springer Verlag, Berlin
Sun C, Fang C, Stephen Z, Veiseh O, Hansen S, Lee D, Ellenbogen RG, Olson J, Zhang M (2008) Tumor-targeted drug delivery and MRI contrast enhancement by chlorotoxin-conjugated iron oxide nanoparticles. Nanomedicine 3(4):495-505

Sun T, Yan Y, Zhao Y, Guo F, Jiang C (2012) Copper oxide nanoparticles induce autophagic cell death in A549 cells. PLoS ONE 7(8):e43442

Varukattu NB, Vivek R, Rejeeth C, Thangam R, Ponraj T, Sharma A, Kannan S (2020) Nanostructured pH-responsive biocompatible chitosan coated copper oxide nanoparticles: a polymeric smart intracellular delivery system for doxorubicin in breast cancer cells. Arabian J Chem 13(1):2276-2286

Veiseh O, Kievit FM, Fang C, Mu N, Jana S, Leung MC, Mok H, Ellenbogen RG, Park JO, Zhang M (2010) Chlorotoxin bound magnetic nanovector tailored for cancer cell targeting, imaging, and siRNA delivery. Biomaterials 31(31):8032-8042

Vivek R, Thangam R, NipunBabu V, Rejeeth C, Sivasubramanian S, Gunasekaran P, Muthuchelian K, Kannan S (2014) Multifunctional HER2-antibody conjugated polymeric nanocarrier-based drug delivery system for multi-drug-resistant breast cancer therapy. ACS Appl Mater Interfaces 6(9):6469-6480

Wei Y, Liang J, Zheng X, Pi C, Liu H, Yang H, Zou Y, Ye Y, Zhao L (2017) Lungtargeting drug delivery system of baicalin-loaded nanoliposomes: development, biodistribution in rabbits, and pharmacodynamics in nude mice bearing orthotopic human lung cancer. Int J Nanomed 12:251-261

Zhang H, Li J, Hu Y, Shen M, Shi X, Zhang G (2016) Folic acid-targeted iron oxide nanoparticles as contrast agents for magnetic resonance imaging of human ovarian cancer. J Ovarian Res 9(1):19

Zhang T, Chen Y, Ge Y, Hu Y, Li M, Jin Y (2018) Inhalation treatment of primary lung cancer using liposomal curcumin dry powder inhalers. Acta Pharmaceutica Sinica B 8(3):440-448

\section{Publisher's Note}

Springer Nature remains neutral with regard to jurisdictional claims in published maps and institutional affiliations.

\section{Submit your manuscript to a SpringerOpen ${ }^{\circ}$ journal and benefit from:}

- Convenient online submission

- Rigorous peer review

- Open access: articles freely available online

- High visibility within the field

- Retaining the copyright to your article

Submit your next manuscript at $\gg$ springeropen.com 